\title{
Article
}

\section{Approach to the Formulation of the Variable Change Theorem}

\author{
Armando Morales Carballo ${ }^{1}$, Edgardo Locia Espinoza ${ }^{1}$, José M. Sigarreta Almira ${ }^{1}$ and Ismael G. Yero ${ }^{2, *(D)}$ \\ 1 Facultad de Matemáticas, Universidad Autónoma de Guerrero, Acapulco 39074, Mexico; \\ armandomorales@uagro.mx (A.M.C.); 08626@uagro.mx (E.L.E.); 14366@uagro.mx (J.M.S.A.) \\ 2 Departamento de Matemáticas, Universidad de Cádiz, 11202 Algeciras, Spain \\ * Correspondence: ismael.gonzalez@uca.es
}

Citation: Carballo, A.M.; Locia Espinoza, E.; Sigarreta Almira, J.M.; Yero, I.G. Approach to the

Formulation of the Variable Change Theorem. Educ. Sci. 2021, 11, 357. https://doi.org/10.3390/ educsci11070357

Academic Editors: Pascual D. Diago Nebot and Dionisio F. Yáñez

Received: 10 June 2021

Accepted: 14 July 2021

Published: 16 July 2021

Publisher's Note: MDPI stays neutral with regard to jurisdictional claims in published maps and institutional affiliations.

Copyright: (C) 2021 by the authors. Licensee MDPI, Basel, Switzerland. This article is an open access article distributed under the terms and conditions of the Creative Commons Attribution (CC BY) license (https:/ / creativecommons.org/licenses/by/ $4.0 /)$.

\begin{abstract}
This research proposes a didactic strategy to enrich the assimilation processes of the change of variable theorem in solving the definite integral. The theoretical foundations that support it are based on the contributions of social constructivism, problem solving, and treatment of theorems. The practical validation of the strategy is carried out with students of the Higher Technical Level in Applied Mathematics at the Autonomous University of Guerrero.
\end{abstract}

Keywords: assimilation; change of variable theorem; teaching-learning; definite integral

\section{Introduction}

The origin of integration undoubtedly comes from several problems of geometric order posed by the Ancient Greeks, such as, for instance, calculation of areas (or squares), volumes, lengths, or centers of gravity. Some of the Greek precursors of the integral calculus can be summed up in Eudoxus and Archimedes. The European mathematicians of the seventeenth century (Cavalieri, Torricelli, Roberval, Fermat, Pascal) used Archimedean methods and the method of indivisibles to perform numerous quadratures, in particular, that of the area under the equation curve $y=x^{n}$ (with $n$ natural), up to the abscissa $a$. The methods used revealed the underlying concepts that were not be fully clarified until the nineteenth century: the limit and Riemann sums. The efficiency in the calculus of these early "integralists" is astonishing. However, Leibniz and Newton indeed gave decisive progress to the history of integration, organized around the Fundamental Theorem of Calculus (that of the reciprocity between integration and derivation) and a system of notations that allowed the integral calculus to access generality. In the eighteenth and nineteenth centuries, analysis developed in an extraordinary way, but before Cauchy, there was almost no concern to exactly define what was being talked about. However, the reflection of mathematicians returns to focus on the integral, regarding one of the great problems of the nineteenth century, that of the Fourier series deduced from a function. Therefore, Cauchy tried to define the integral over a segment of a continuous function with the help of "Riemann's" sums (1823). Riemann, from his part, in 1854 investigated under what conditions the sums bearing his name converge when "the norm of the partition" tends to zero.

In the calculus of one variable functions, the Riemann integral is a way of defining the integral over a segment of a bounded and continuous function (although it is not analyzed in this study, it is known that it can guarantee the existence of the integral when the set of discontinuities of the function is a set of measure zero). In geometric terms, if the function is non-negative, this integral is interpreted as the area of the region under the representative curve of the function. The general procedure used to define the Riemann integral is the approximation, and then the step to the limit, by the so-called Riemann sums, which in the case that the function is non-negative, is interpreted as an approximation to the area under the curve through the sum of areas of rectangles.

In the study of the definite integral, the change of variable is a transformation tool that allows to reduce mathematical problems into models and/or expressions, for which 
techniques and procedures are known to successfully find their solution. When talking about the Fundamental Theorem of Calculus, we refer to the theorem that states that derivation and integration are inverse processes, more precisely: "If $f$ is a continuous function defined on an interval $(a, b)$ and $F$ is the function defined for all $x \in(a, b)$ as $F(x)=\int_{a}^{x} f(t) d t$, then $F$ is differentiable, and also $F^{\prime}(x)=f(x), \forall x \in(a, b)$ as well as, if $G$ is any primitive of $f$ in $(a, b)$, then $\int_{a}^{b} f(t) d t=G(b)-G(a)^{\prime \prime}$. In particular, in the solution treatment of the integral, the variable change theorem plays an important role as an integrating element of the content. In addition, this theorem is based on the fundamental theorem of integral calculus, which makes its methodological treatment interesting as a theoretical element for the development of the topic of the definite integral.

Aldana and González [1] showed that learning the concept of the definite integral presents difficulties for students, which are mainly manifested through its mechanical, algorithmic, and memory use. While Ricardo and Moya [2] believe that to favor the assimilation of theorems, students should feel the need to argue and should be motivated to search for them. This process must achieve in students learning characterized by independence and creativity, logical reasoning, and abilities to search for propositions, among others. Olave [3] states that students develop their own ways of understanding and working on the contents when facing the calculation of the area under a curve without having previously received specific instruction on this topic. They commonly use two basic procedures: the division of the region into known figures for which they believe they have tools to determine their areas, and the other the "visual estimation".

On the other hand, Ponce and Rivera [4] established that it is common to see the study of the primitives of functions in books concerning calculus; however, most authors pay little attention to the domains over which the primitives are valid, which might lead to mistakes while evaluating definite integrals. The authors highlight this situation by using the universal trigonometric substitution to calculate the area under a given curve. This situation was also corroborated by the authors of the present work, when reviewing the textbooks commonly used for the teaching of Calculus at the Autonomous University of Guerrero. In addition, it was identified that these texts deal with the variable change technique for the solution of the definite integral, but without focusing on geometric analysis to understand its meaning.

Llorens and Santonja [5] documented that, in general, university students identify "integral" with "primitive", while the "definite integrals" are identified with Barrow's rule, even when it cannot be applied, and the concept of area is not integrated with that of the definite integral so that a purely algebraic interpretation of the integral persists. Mejía [6] reports work on the perception of the notions of conservation, comparison, and quantification of the area by university students, in order to show from their arguments how they perceive that the area is conserved and quantified. One of the proposed activities there was to solve the integral $\int_{0}^{1} x\left(x^{2}+1\right)^{2} d x$. The students established that the guarantee for the area to be conserved is related to the change of the variable. However, they do not usually wonder about the nature of the new variable. A comment that we can add here is that to solve the integral $\int_{0}^{1} x\left(x^{2}+1\right)^{2} d x$, it is indeed not necessary to use the Change of Variable Theorem because if the integrand is developed, a polynomial of degree 5 is obtained, whose integral is found by directly applying the Fundamental Theorem of Calculus. However, in the baseline research, it is identified that part of the objective is to investigate whether the students who made up the experimental group adequately use other alternative methods to solve the integral, such as the change of variable. The students established that a guarantee to conserve the area is related to the change of variable, without asking about the nature of the new variable and about the sign of the integrand function. This type of situation justifies the study of the theorem of the change of variable.

Regarding the assimilation of the variable change theorem in the solution of the definite integral, Cabañas and Cantoral [7]; Díaz, Cruz, Velázquez, and Molina [8]; Morales [9]; Paschos and Faumak [10]; and Schoenfeld [11] revealed multiple difficulties. Just as an example, we describe the following: to move from a geometric representation to an analytic 
one through the definite integral, students use the change of variable to solve the definite integral without attending to the necessary conditions that allow this change to be made. In this regard, they present insufficiencies to argue the geometric meaning of the change of variable, as well as they do not see the relationship between the Variable Change Theorem with the Fundamental Theorem of Calculus. In particular, Schoenfeld [11] exemplifies the importance of the problem-solving process associated with the calculation of the definite integral when he proposed to the students solving the following integral $\int \frac{x}{x^{2}-9} d x$.

Based on the aforementioned information, we propose to focus this research on the study of the variable change theorem for the resolution of the definite integral and thus contribute to favor its assimilation within the teaching-learning process of Integral Calculus. Therefore, the objective was to develop and apply a didactic strategy to promote the assimilation of the variable change theorem through problem-solving in students of the Higher Technical University level in Applied Mathematics of the Faculty of Mathematics of the Autonomous University of Guerrero, Mexico.

\section{Theoretical-Methodological Foundations of the Research}

This research focuses on the contributions of social constructivism, which has its theoretical bases in the works developed by Lev Semiónovich Vygotsky (1896-1934) and collaborators, and Jean Piaget (1896-1980) and collaborators. From this theoretical perspective, it is considered that the process of assimilation of the human psyche is given on the basis of social experience and, furthermore, it is considered that it is the social relationships that occur at a given time and under a given cultural condition that contribute to the development of knowledge of man.

In this sense, Ferreiro [12,13]; and García, Ortiz, Martínez, and Tintorer [14] highlight the importance of man's activity mediated by historical and cultural influences. Thus, assimilation in the subject begins when it acts on the objects of knowledge through a system of actions and operations. That is, when the subject approaches the objects of knowledge, it does so through the mental structures that it has acquired in its performance and its social experience, but it is also necessary for the subject to act on objects through tools or sociocultural signs.

Starting from constructivist positions, the system of actions and operations, both physical and mental, is assumed as didactic strategies, which facilitate the confrontation (interactivity) of the subject who learns with the object of knowledge, and the relationship of help and cooperation with other colleagues during the learning process (interaction) to perform a task with the required quality. These strategies constitute mediation tools between the learner and the teaching content that the teacher consciously uses to achieve certain learning (see Ferreiro [12,13]).

The analysis carried out allowed us to discern the similarities and discrepancies between the different positions and perspectives regarding the assimilation process developed by Ausubel [15], Ballester et al. [16], Gagné [17], Galperin [18], García et al. [14], Leontiev [19], Piaget [20], and Rogers [21], in order to take a position that favors our research. Thus, assimilation from the integrating positions of social constructivism is assumed as a "cognitive process supported by the mental structures that the individuals have acquired in their social relationships (previous knowledge, experiences, skills, habits, and motivations); that allows the understanding, updating, development, and application of a certain knowledge". For our study, the process of assimilation of theorems will be structured by the following stages: understanding, identification, fixation, application, and evaluation.

As our objective is the assimilation of theorems, we will approach the partial processes of theorem treatment through problem solving in a way that allows the student to formulate a conjecture and/or assumption. In this direction, we propose a set of theoretical-practical knowledge based on methods, strategies, principles, and procedures that the teacher must consider to guide the student during the teaching-learning process of mathematical content. 
Mathematical theorems express the relationships between the concepts that are addressed. Their treatment in the teaching of Mathematics allow the development of multiple mathematical skills. With the methodological treatment of theorems, it is intended that students understand the mathematical and functional essence of the relationships expressed in them and that they can apply them in the foundation of their statements and reasoning, as well as in the resolution of intra-mathematical and extra-mathematical problems (Ballester et al. [16]; Cruz [22]; Martínez, Infante, and Brito [23]). From the methodological point of view, the treatment of theorems in order to favor their assimilation is structured in two stages, as identified in Table 1.

Table 1. Methodological structure of theorems.

\begin{tabular}{ll}
\hline \multicolumn{1}{c}{ Theorems } & \multicolumn{1}{c}{ Actions } \\
\hline \multirow{3}{*}{ Search for the theorem } & -Search for assumptions \\
& -State a thesis \\
& -Formulate a theorem \\
\hline \multirow{3}{*}{ Search for the proof } & -Find an idea of the proof \\
& -Come up with a demonstration plan \\
& -Develop or complete the proof \\
\hline
\end{tabular}

The objective of the didactic strategy focuses on enabling students to search and formulate a certain theorem from the resolution of a structured system of problems. For the methodological structuring, specific aspects of the processes for the search of theorems are presented below: the actions and operations of the teacher and the students must be directed to carry out a work process with specific activities (problem system) that allow establishing a certain assumption or conjecture. In this sense, the partial search is directly related to the heuristic resources and the resolution. Among the heuristic resources, the following will be taken into account, among others: testing, checking, applying analogies, observation of partial examples, observation of special cases, limit cases, substituting concepts for operant definitions, formulation of reciprocals, and formulation of the assumption.

In particular, to favor the assimilation of theorems, it is the teacher's task to consider the level of development reached by the students, the systematization of the classes or activities, and their partial objectives to be achieved in each one of them. The teacher is in charge of guiding and creating the necessary conditions to achieve the objectives through meaningful learning. Among the aspects to be developed in the student with the treatment of the search of theorems, the following should be considered: arguing and supporting truth values of propositions, reformulating known propositions, knowing how to deny them and find their reciprocals, establish relationships with other known theorems and formulate an assumption.

The practical way of treating theorems is developed through problem-solving, in which a series of logical inferences are constructed to find or verify a certain assumption. Some important actions to favor the process of assimilation of theorems from problemsolving are the exercise, deepening, and systematization of knowledge associated with the theorem to be treated.

The exercise is carried out to set skills, such as being able to identify the premises of theorems in different conditions, as well as helping to deduce the conclusions from them. The deepening is aimed at understanding the statement of the theorem and its recognition when it is presented in different contexts. In this process, the student must have mastery of the language and critical thinking to carry out the tasks (formation of reciprocals, negations, and oppositions) proposed to achieve the deepening of the treatment of theorems. In the systematization, common and different properties are analyzed, and the relationships between the different components of knowledge are made visible. This allows the articulation of isolated facts in the structure of knowledge. That is, a knowledge system is built, taking into account the handling of heuristic resources. 
In this part, heuristic processes play a fundamental role both in problem-solving and in the methodological treatment of the theorem. For example, analogies can be applied, observations are made, analysis of examples and counterexamples are studied, special cases are studied, and the possibility of forming reciprocals of known theorems is measured, tested, and compared, and transformations of type are made: geometric, analytical, and algebraic. It is worth mentioning that problem solving goes beyond applying formulas since it stimulates the ability to create, discover, elaborate hypotheses, confront, reflect, argue, communicate ideas, reason, and analyze situations and then solve them (Pérez and Ramírez [24]).

In other investigations, such as that of Cedeño, Caballero, Alcívar, and Macías [25]; Murcia and Valdivieso [26]; and Silva, Rodríguez, and Santillan [27], problem-solving is used as a strategy for teaching and learning mathematics. This allowed us to conclude that the development of skills has been achieved through problem-solving, experience, and improvement of verification, conjecturing, and results validation processes. In particular, Silva, Rodríguez, and Santillan [27], which are based on the Constructivist Theory of learning, highlight the importance of "previous knowledge" which is essential for success in solving problems, especially those that contain specific concepts, in which case, the conceptual errors block the resolution process, also clarify the tendency to memorize formulas instead of their understanding and application.

Mathematical problems have been used as: learning objective, teaching activity, learning instrument, and evaluative element, among other uses, according to the interests of researchers or teachers. Currently, the resolution of mathematical problems has become an important resource to promote the development of students. This situation is in direct relation with the fundamental objective of the teaching of mathematics, learning to solve problems, which means generating the skills to formulate, reformulate, and solve problems, verify their solutions, and make generalizations. For the elaboration of the problems associated with the variable change theorem, we will work with the characterization of the problem posed by Sigarreta and Laborde [28] (p. 16):

1. There will be an initial situation and a final situation.

2. The route from one situation to another one must be unknown or cannot be accessed immediately.

3. There must be a student who wants to solve it and has the necessary elements to seek relationships that allow him to transform the situation.

For Rubinstein [29] the mental process is a regulated act oriented towards the solution of a certain task or a certain problem and is, therefore, linked to practice and to the entire psychic life of the individual, as a system of intellectual actions. In turn, the actions are based on operations, that is, on the ways, procedures, methods, and forms, by which the action takes place. Thus, actions are subordinate in the activity process to an objective and operates according to the conditions in which the activity takes place.

In this way, the activities and problems proposed by the teacher, as well as the actions and operations, must be designed with a particular objective so that the general objectives are achieved together. Knowing the particular and general objectives can serve as a regulating element of the process by allowing the teacher to guide its activity. Considering the system of activities, the designed problems and the results of the diagnosis, the teacher must work on the deficiencies that the students show for the assimilation of theorems. According to the analysis carried out regarding the resolution of problems, the strategies proposed for such a process are integrated by stages, which allow the teacher and the student to keep control to carry out pertinent actions and operations, favoring the achievement of the objectives in each stage. This work aims to promote the assimilation of theorems which will be approached for problem-solving. For this, it is important to assume a position on the strategy and the stages that are considered necessary to achieve this objective.

Cala, Buendía, and Herrera [30]; Campistrous and Rizo [31]; Campos [32]; Pérez and Ramírez [24]; Polya [33]; Santos-Trigo, Moreno-Armella, and Camacho-Machín [34]; Sigarreta and Laborde [28]; Silva, Rodríguez, and Santillan [27]; Schoenfeld [11,35]; Valle 
and Curotto [36], among others, have focused their works on the problem-solving process proposing different techniques and strategies, which refer to a pattern of decisions that must be taken into account to achieve the acquisition, retention, and use of information, which serves to achieve a certain objective when solving a problem. Based on the aforementioned investigations, the following problem-solving strategy will be implemented in this work:

- Action 1. Approach to the problem.

- Action 2. Deepening the problem.

- Action 3. Selection of a work path.

- Action 4. Application of the selected route.

- Action 5. Assessment.

\section{Didactic Strategy to Favor the Assimilation of Theorems}

The relationship between problem solving and Theorem Assimilation essentially lies in the fact that both typical situations of mathematics teaching require processes of search, representation, demonstration, and application, in order to reach the solution of a problem in the first case; and in the second case, through partial processes, seek a formulation and/or reformulation of the theorem and a possible proof. In addition, with both activities, the development of logical-mathematical thinking in students is favored. Here are some methodological guidelines to guide the assimilation process:

Diagnose the student's preparation for the demands of the teaching-learning process, level of achievement, and potential associated with the learning content, intellectual, and evaluative development.

Orient the motivation towards the objective of the activity and maintain its constancy. Develop the need to learn and train into how to do it. Present the topic, subtopic, or class from the approach of a problem situation.

Organize and structure the teaching-learning process through a system of activities for the search and exploration of knowledge, taking into account the actions that the student must carry out in the different stages, which stimulates and encourages the development of thinking, cognitive independence, and habits.

Develop forms of collective activity and communication that favor intellectual development, achieving adequate interaction between the individual and the general cases in the learning process. Promoting student self-knowledge and self-regulation.

Address individual differences in the development of students in the transition from the level achieved towards which they aspire.

Link the learning content with social practice and stimulate its evaluation.

Considering the elements previously analyzed, both of a theoretical and methodological nature, the following didactic strategy (appearing in Table 2) is proposed to favor the assimilation of theorems through problem-solving.

Table 2. Didactic strategy to favor the assimilation of theorems through problem-solving.

\begin{tabular}{lll}
\hline Strategy for Solving Problems & Stages of the Assimilation Process & Operations \\
\hline & $\begin{array}{l}\text {-Read the problem. } \\
\text {-Are all the terms involved in formulating the problem familiar to you? } \\
\text {-State the problem in your own words, specify what is given and what is } \\
\text { sought, identify the knowledge that is related to what is given and what } \\
\text { is sought. }\end{array}$ \\
$\begin{array}{ll}\text { Comprehension } & \text {-Is it an intra-mathematical or extra-mathematical problem? } \\
& \text {-What field of knowledge can you associate the problem with? } \\
& \text { - Does it require the use of mathematical knowledge? } \\
& \text { - Have you seen any other one formulated in a similar way? } \\
& \text {-Is it a problem related to your sociocultural environment? }\end{array}$ \\
\hline
\end{tabular}


Table 2. Cont.

\begin{tabular}{|c|c|c|}
\hline Strategy for Solving Problems & Stages of the Assimilation Process & Operations \\
\hline Deepening the problem & Identification & $\begin{array}{l}\text {-Determine the necessary knowledge to face the problem. } \\
\text {-Have you seen any other one formulated in a similar way? } \\
\text {-Establish analogies, experiment with other data, and } \\
\text { propose regularities. } \\
\text {-Have all possible cases been checked? } \\
\text {-Underline the expressions that you consider to have the greatest } \\
\text { semantic value in the problem. } \\
\text {-Look for synonyms and antonyms of the terms that you } \\
\text { consider fundamental. } \\
\text {-Establishes the unknown(s), that is, what is being sought. } \\
\text {-Determine the data that are given directly in the formulation of } \\
\text { the problem. } \\
\text {-Between what values should it be found? } \\
\text {-In a second moment you can think of developing a scheme, diagram, } \\
\text { table, etc. } \\
\text {-Is there enough, or is there too much data? } \\
\text {-Are there contradictory elements? }\end{array}$ \\
\hline Selecting a work path & Fixation & $\begin{array}{l}\text {-Transform the problem into another equivalent one. } \\
\text {-How can the data be related to the unknown(s)? } \\
\text {-What inferences can be made from the data found? } \\
\text {-Evaluate counterexamples. } \\
\text {-Correctly use mathematical terminology and symbols. } \\
\text {-Choose an appropriate language or a suitable notation. } \\
\text {-Define what knowledge is related to the elements of the problem. } \\
\text {-Justify ideas, judgments, and arguments. } \\
\text {-Select the properties or definitions that may be useful to you. } \\
\text {-Assume the problem is solved. } \\
\text {-In which field of knowledge does the proposed problem move: } \\
\text { arithmetic, algebraic, or geometric? } \\
\text {-Define which knowledge system is related to the elements of } \\
\text { the problem. } \\
\text {-Which one of them is related to the premise or thesis of the problem? } \\
\text {-Could a possible answer be given? }\end{array}$ \\
\hline Application of the selected route & Application & $\begin{array}{l}\text {-Establish relationships in correspondence with the forms of work. } \\
\text {-Use cognitive and metacognitive strategies. } \\
\text {-Execute an action plan and consciously apply the procedures. } \\
\text {-Make equivalent transformations in the premise and/or the thesis. } \\
\text {-Analyze the possible ways of solution. } \\
\text {-Consider particular and general cases. } \\
\text {-Integrate the possible results so that they can be used in } \\
\text { different contexts. } \\
\text {-Can you apply that same work technique to another situation? } \\
\text {-Can the method used to solve other problems be generalized? } \\
\text {-Make assumptions based on possible solutions. }\end{array}$ \\
\hline $\begin{array}{l}\text { Assessment. } \\
\text { Consider and take a critical } \\
\text { stance on the system of actions } \\
\text { and operations carried out }\end{array}$ & Valoration & $\begin{array}{l}\text {-What conjectures can you make? } \\
\text {-Analyze the steps and actions taken; analyze errors and their possible } \\
\text { causes; specify how to avoid errors. } \\
\text {-Explain the reasoning process carried out and give details about it. } \\
\text {-Think upon the procedures and methods used. } \\
\text {-Choose an appropriate language or a suitable notation. } \\
\text {-Are all the solutions found for the problem? } \\
\text {-Explain with your words how you arrived at the solution. } \\
\text {-Does the answer given make sense in relation to your experience? } \\
\text {-Does the proposed solution really answer the problem in question? } \\
\text {-What have you contributed from the social and/or mathematical point } \\
\text { of view with the work on the problem? }\end{array}$ \\
\hline
\end{tabular}

\section{Application of the Didactic Strategy to Favor the Assimilation of the Variable Change Theorem}

It is wise to argue that there are variations in the statement of the variable change theorem in textbooks, depending on the authors. Essentially, the variations occur under the conditions that a function $u=g(t)$ that performs the change of variable must satisfy. Before proceeding to the application of the strategy, it is essential to carry out an analysis of the theorem to be treated, in this case, that of the change of variables in definite integrals, 
which will be analyzed in the following terms: suppose that $g$ has a continuous derivative in the interval $I=\left[a^{\prime}, b^{\prime}\right]$, and that $f$ is continuous in the image (range) of $g$. Then, for every $a, b \in I, \int_{a}^{b} f(g(t)) g^{\prime}(t) d t=\int_{g(a)}^{g(b)} f(u) d u$. Notice that the formula under attention follows from the fundamental theorem and from the chain rule of differentiation where is an antiderivative of.

Note that the theorem has several hypotheses; in compliance with these, we guarantee that the equality between the two integrals occurs. If some of the hypotheses are not fulfilled, then this equality does not necessarily have to be fulfilled. An important methodological element to take into account in the process of assimilation of theorems is to verify that if we suppress some of the hypotheses, the result may be false.

With regard to the hypothesis of the continuity of $f$, it should be noted that the change of variable theorem is in direct relation to the fundamental theorem of calculus, and this requires that the integrand will be a continuous function on the integration interval. It is known in university mathematics that a function is integrable according to Riemann if the set of discontinuities is of zero measure; however, at the upper middle level (which is where this research is contextualized), we only work with functions that do not have this type of "pathologies". It is possible to prove the change of variable theorem for the case in which the integrand is a Riemann-integrable function (not necessarily continuous), but this analysis goes beyond the objectives of this work.

\subsection{Experimental Population}

The application of the strategy to favor the assimilation of the Variable Change Theorem in the resolution of the Definite Integral was developed with the 16 students of the specialty "Técnico Superior Universitario en Matemáticas Aplicadas" from the Autonomous University of Guerrero, who were studying the matter of Differential and Integral Calculus II. A system of activities related to the change of variable theorem was designed to solve the definite integral. For the design of the activities, the theoretical and methodological aspects described above and the necessary mathematical content were taken into account. The design consisted of a diagnosis and a system of standard problems associated with each of the stages of the assimilation process.

The students had already addressed the change of variable to find primitives, so a diagnosis was applied to them that fulfilled the function of knowing the previous conditions and their basic knowledge in order to successfully deal with the treatment of the variable change theorem for definite integrals. More precisely, its conceptual, operational, and/or procedural bases were identified.

Authors should discuss the results and how they can be interpreted from the perspective of previous studies and of the working hypotheses. The findings and their implications should be discussed in the broadest context possible. Future research directions may also be highlighted.

\subsection{Activity Design and Application Dynamics}

The application of the strategy was developed in six sessions of approximately $1 \mathrm{~h}$ and 30 min each. For the analysis of the results associated with the application of the strategy, its implementation is documented. Below we present some of the typical problems developed in the class sessions.

The didactic strategy is of a general nature; that is, it can be applied in general to the treatment of any theorem. In particular, in the stage of approaching the problem, as a basic element for the assimilation of the Variable Change Theorem, it is assumed that students know the basic derivation and integration formulas, as given in Table 3. 
Table 3. Some direct integrals.

\begin{tabular}{ccc}
\hline $\int x^{\alpha} d x=\frac{x^{\alpha+1}}{\alpha+1}+C, \alpha \neq-1$ & $\int \frac{d x}{x}=\ln |x|+C$ & $\int \sin x d x=-\cos x+C$ \\
\hline $\int \cos x d x=\sin x+C$ & $\int \frac{d x}{\cos ^{2} x}=\tan x+C$ & $\int \frac{d x}{\sin ^{2} x}=-\cot x+C$ \\
\hline $\int \tan x d x=-\ln |\cos x|+C$ & $\int \cot x d x=\ln |\sin x|+C$ & $\int \frac{a^{x}}{x} d x=\frac{a^{x}}{\ln a}+C$ \\
\hline $\int \frac{d x}{a^{2}+x^{2}}=\frac{1}{a} \arctan \frac{x}{a}+C$ & $\int \frac{d x}{a^{2}-x^{2}}=\frac{1}{2 a} \ln \left|\frac{a+x}{a-x}\right|+C$ & $\int \frac{d x}{\sqrt{a^{2}-x^{2}}}=\arcsin \frac{x}{a}+C$ \\
\hline
\end{tabular}

If there is not this knowledge, then the conditions are not ensured to enable the fulfillment of this stage in the strategy for assimilation.

It is important to notice that every function $f$, continuous on the interval $(a, b)$ has a primitive function in this interval. However, not every primitive function, even when it exists, can be expressed through a finite number of operations with elementary functions, so the integration methods discussed in high school are not useful to find the integrals of functions such as $f(x)=e^{-x^{2}}$ or $g(x)=\frac{\sin x}{x}$, and one has to use, for example, numerical methods to approximate their values.

The didactic strategy favors a systematic approach to the Variable Change Theorem in definite integrals, favoring its construction process. Unlike what happens in traditional teaching, in which the teacher states the theorem and performs the proof, the strategy allows students to identify relationships and regularities between the elements of the theorem that are revealed by the examples presented until the explicit formulation and application of the theorem.

Analysis and Discussions

1. Let $f(x)=a x$ be a given function, where $a$ is a constant.

(a) Determine the value of $a$ to verify that the area of the region under the curve $f(x)=a x$, above the horizontal axis, and between the lines $x=0$ and $x=4$, is 16 square units.

(b) Can we construct another region bounded superiorly by the curve of $f(x)=a x$, inferiorly by the horizontal axis, and laterally by the lines $x=x_{1}, x=x_{2}$, whose area is 16 square units? Argue your answer and determine, if possible, the values of $a, x_{1}$, and $x_{2}$.

(c) What relationships exist between the previously constructed regions, based on their shape and area, respectively? Discuss your answers.

Objective: To understand the change of variable in the integration regions and its relationship with the definite integral.

Observations (a): it was identified that 11 of the 16 students carried out the activity: three of them determined the value of the parameter $a=2$ by calculating 16 equal to the integral they raised in the interval [0,4]; three students proceeded by trial and error, until the value of the parameter $a=2$ was established; one student equaled the integral with 16 , but incorrectly solved the equation; four students only raised the integral $\int_{0}^{4} a x d x$ without solving it. By analyzing the productions, three students were able to recognize the definite integral as a method to solve problems associated with determining the area of a region.

Observations (b): this activity is fundamental since from here, we begin to work with the meaning of the change of variable. From the 16 students, only one of them raised the following values $a=8, x_{1}=0, x_{2}=2$. Then, when solving the definite integral $\int_{0}^{2} 8 x d x$, he determined the value 16. In this case, the student accepts that the region changed its shape, but according to the calculations made, the measure of its area is preserved. He stated that a transformation has occurred but did not argue the analytic relationship of the integrals $\int_{0}^{4} 2 x d x$ and $\int_{0}^{2} 8 x d x$. The rest established that the activity cannot be resolved since there is no function that meets the requirements. Others tended to proceed in the wrong way; after the teacher reoriented them, the difficulty of the activity was reduced.

Observations (c): the students were expected to argue about the shapes of the regions and the relationship of their areas, regarding the process of transformation from one region 
to another region, among other arguments. The student who correctly answered the previous question in part (b) established that only the shapes of the regions change, but the measurements of their areas are maintained; 10 students considered that if they could determine the function in part (b), they would have changed just their shapes, but their area measurements would be the same. Note that despite not having answered the activity in part (b) correctly, they conjectured about the possibility of equality of the areas of the regions under a curve. The rest established that the measures of the areas are different along with their forms; however, they do not make an argument as to why.

Section (a) was answered correctly by 11 and incorrectly by 5; in Section (c), the same result was obtained, and Section (b) was only answered correctly by one student.

2. Figure 1 shows two regions in the plane with the same area.

(a) How can you justify that, in fact, the areas of the regions are equal?

(b) What are the implications of making a variable change?

(c) What effects does the application of the Variable Change Theorem have on the resolution of the integral $\int_{0}^{2} \frac{1}{2}\left(\frac{1}{2} x+1\right)^{3} d x$ ?

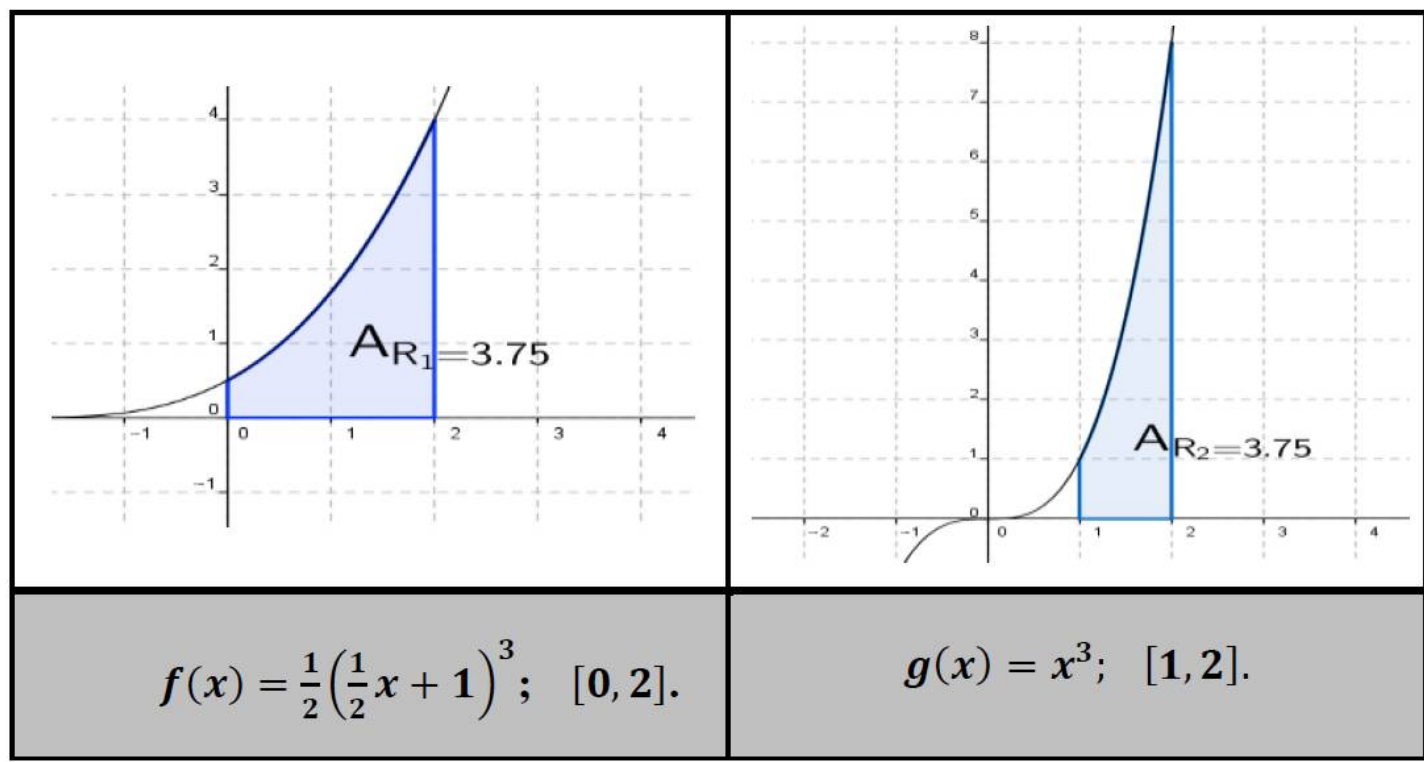

Figure 1. Integration regions.

Objective: To establish the scope and implications of the change of variable in the resolution of definite integrals.

Observations (a): 11 of the 16 students correctly carried out the transformation under the change of variable, as predicted. They also established that one way to verify the equivalences is by solving the integrals in the indicated intervals, and the rest did not perform the activity.

Observations (b): we present some responses obtained by the students:

- Student B: choose a suitable substitution for a variable in such a way that its derivative is related to the original function, and thus, it remains in simpler terms.

- Student F: to change a variable is to take a function to a simpler one. For this, we modify the evaluation interval that depends on the new variable that has been chosen.

- Student N: it helps us to make our work easier, but it is not always necessary to do so.

- Student P: transform the function in a certain interval into another function defined in another interval, of which it is easy to calculate the area delimited by the same function.

(Student responses, 2020) 
Observations (c): seven students established that the change of variable modifies the integration intervals, but not the value of the main integral; four established that the change of variable facilitates the integration process; one stated that under the change of variable, the shape of the region is modified, and the rest of the students presented incorrect answers.

As could be seen, in an atmosphere of debate about the activities that the students carry out, intuitive ideas emerge very close to the effects that the change of variable actually makes in the solution of the definite integral. Item (a) was answered correctly by 11 and incorrectly by 5; Item (b), 4 correct and 12 incorrect answers were obtained; and Item (c) was answered correctly by 12 students.

We observe that four students out of the total (B, F, N, and P), despite not formally arguing the uses of the change of variable, showed ideas close to the formal aspect of said meaning.

3. Represent the region bounded superiorly by the curve $f(x)=x+1$, inferiorly by the horizontal axis and by the lines $x=0$, and $x=4$.

(a) Make a graphical representation of the region and calculate its area without using integral calculus.

(b) To calculate the area of the region above, the following integral $A(R)=\int_{0}^{4}(x+1) d x$ is proposed. Applying the change of variable, $u=x+1$, with $d u=d x$, it follows that $A(R)=\int_{0}^{4}(x+1) d x=\int_{0}^{4} u d u=\frac{4^{2}}{2}=8$. Discuss the obtained results.

Objective: to fix the theorem of the change of variable of the definite integral, in particular, to recognize the error associated with the region of integration.

Observations (b): in the group discussion, it was analyzed that the limited region was a trapezoid, and its formula was recalled. Seven of the students were able to correctly argue the equivalence between the methods for calculating the area and identified the error in the limits of integration when applying this theorem; the rest argued errors related to the formula of the trapezoid, area of the trapezoid, or failed to recognize any error in the presented procedure. Here are some of the given answers.

- Student L: I do not see any errors.

- Student H: The figure shown is not a trapezoid.

4. Determine the value of the integral $\int_{\frac{\pi}{4}}^{\frac{\pi}{2}} \frac{\cos x}{\sin x} d x$. Figure 2 shows the region under the curve $f(x)=\frac{\cos x}{\sin x}$ above the horizontal axis, and between the lines $x=\frac{\pi}{4}$ and $x=\frac{\pi}{2}$.

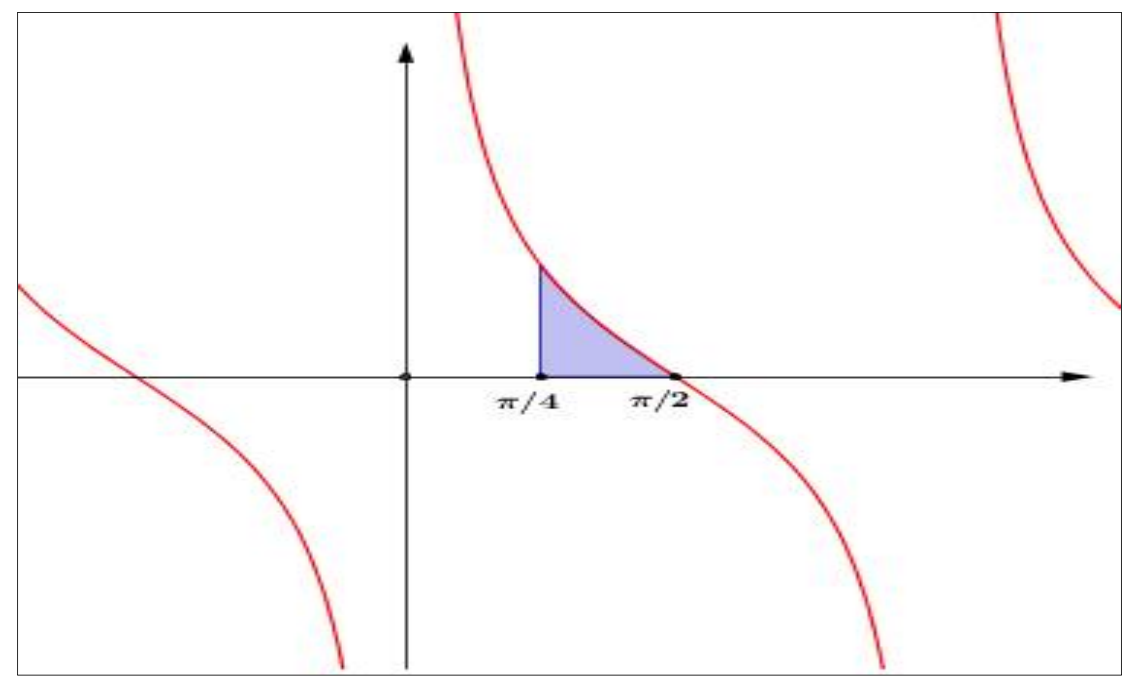

Figure 2. Region of integration in the interval $[\pi / 4, \pi / 2]$.

Objective: to apply the change of variable theorem in the solution of the definite integral. 
Observations: the activity allowed the students who had difficulties in establishing the relationships indicated in the previous activities to understand that the change of variable not only allows the solution of some integrals; but also that they clarified the effects of the change of variable theorem, that is, that it modifies the integration regions only in the form but not in the measure of their area. In this activity, it was identified that nine students arrived at the correct solution of the integral through the change of variable theorem. That is, they make a suitable variable change and identify that under such variable change, the integration intervals are modified. However, it is not very clear how they reached the new integration intervals. We next show one of the productions developed.

- Student E: in order to solve the integral $\int_{\frac{\pi}{4}}^{\frac{\pi}{2}} \frac{\cos x}{\sin x} d x$, we make $u=\sin x, d u=\cos x d x$, evaluate $x=\frac{\pi}{2} \rightarrow \mathrm{u}=1$ and $x=\frac{\pi}{4} \rightarrow u=\frac{1}{\sqrt{2}}$, then

$\int_{\frac{\pi}{4}}^{\frac{\pi}{2}} \frac{\cos x}{\sin x} d x=\int_{\frac{1}{\sqrt{2}}}^{1} \frac{1}{u} d u=\ln (u) \mid \begin{gathered}1 \\ \frac{1}{\sqrt{2}}\end{gathered}=\ln (1)-\ln \left(\frac{1}{\sqrt{2}}\right)=\ln (1)-\ln (1)+\ln (\sqrt{2})=\ln (\sqrt{2})$.

Three students made a change of variable. However, they did not analyze that under such change of variable, the integration intervals are modified. Therefore, they arrived at incorrect solutions. The rest proceeded incorrectly since they did not remember the integration method, some did not identify it, and others did not remember how the function $f(x)=\frac{1}{x}$ is integrated, for $x>0$.

5. Prove that $\int_{0}^{2} 2(x+1)^{2} d x=\int_{1}^{3} 2 u^{2} d u$ ?

Objective: to apply the variable change theorem as a proof method.

Observations: seven students responded correctly to the activity. The answers raised by most of the students (nine) showed that students only associate the theorem of the change of variable as a method of calculation, that is, procedural. They do not recognize the theoretical scope of the theorem as a method of proving or obtaining new mathematical relationships. Below is an answer given by a student who had answered the previous activity correctly.

Student A: I would not know how to prove it.

6. Discuss your answers.

(a) Which is the relationship between $\int_{\frac{\pi}{4}}^{\frac{\pi}{2}} \frac{\cos x}{\sin x} d x$ and $\int_{\frac{1}{\sqrt{2}}}^{1} \frac{1}{x} d x$ ?

(b) While solving a definite integral using the change of variable theorem, what variations can you consider to occur in the main function for the given interval?

Objective: to assess the effects produced by the change of variable in the region of integration and in the calculation of the definite integral.

Observations (a): five students established that the integrals, through a change of variable, transform one into the other one; four established that the regions that allow the curves of these functions to be formed have the same area measure; two students argued that under the change of variable are transformed into another function, only that they are defined in different intervals. The rest of the students did not establish close elements to recognize the relationship; it was not until the group discussion that they identified the requested relationship.

Observations (b): seven students answered the activity correctly; as an example, five answers are shown that we consider yielding elements on an approximation of the students to the elements associated with the theorem of the change of variable in the solution of the definite integral.

- Student B: The integral remains in terms of a function of easy integration; in addition, such change of variable must be adequate.

- Student C: The change of variable is used to put an integral in its simplest way to calculate, now when the change of variable is completed in a definite integral, the intervals of the function change. 
- $\quad$ Student F: The change of variable is a method that allows us to solve integrals, this is completed in order to transform an integral to another simpler one, what the change of variable does is change a function for another simpler one; this implies that the evaluation intervals change with respect to the new variable.

- $\quad$ Student M: What makes the integral less complex by making it easier to integrate, since it changes the integration intervals and is less complex.

- $\quad$ Student Q: The change of variable modifies a function and its intervals of integration in such a way that it produces another function defined in a different interval, but that when integrating it turns out to have the same area as the function on which the change of variable was applied.

(Student responses, 2020)

Although the students' responses are not entirely formal and complete, based on our experience, the statements made by them generally do not appear in our traditional teaching practices. However, with the system of activities proposed and the implementation of the didactic strategy, a possible formulation of the variable change theorem is favored. On the other hand, the rest of the students who did not explain, in the beginning, the meanings of the variable change, after establishing a group debate, managed to formulate a structured idea regarding the elements associated with the activity.

7. Compute, by using the substitution $u=\tan \left(\frac{x}{2}\right)$, the area of the region shown in Figure 3, bounded superiorly by the curve $f(x)=\frac{1}{2+\cos (x)}$, inferiorly by the horizontal axis and laterally along the lines $x=0$ and $x=2 \pi$.

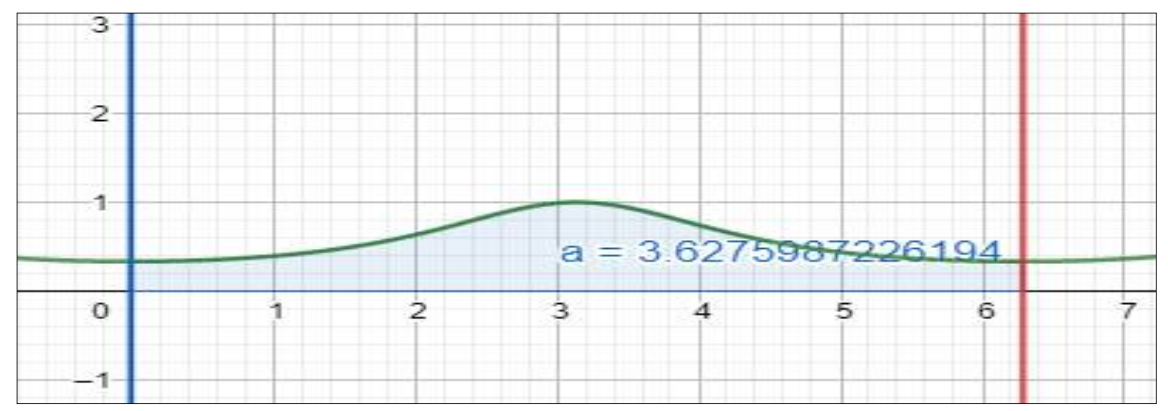

Figure 3. Area under the curve of $f(x)$.

Objective: to evaluate necessary conditions for the application of the variable change theorem.

Observations: when reviewing the answers presented by the students, we identified that only six students managed to establish the condition that was not satisfied for the correct application of the change of variable. We present below the responses obtained by two students who responded correctly to the activity, essentially taking as a basis the limits of integration and the integration function resulting from the application of the change of variable theorem.

- Student H: If we make $u=\tan \left(\frac{x}{2}\right)$, in $\int_{0}^{2 \pi} \frac{1}{2+\cos (x)} d x$, then we obtain that the new limits of integration are $\tan \left(\frac{0}{2}\right)=0=\tan \left(\frac{2 \pi}{2}\right)=\tan (\pi)=0$. It transforms a region with positive area into a point.

- $\quad$ Student K: If we transform the integral $\int_{0}^{2 \pi} \frac{1}{2+\cos (x)} d x$, to an undefined one, and solve it by using the change of universal variable, the integral gives us $\int \frac{1}{2+\cos (x)} d x=\frac{2}{\sqrt{3}} \arctan \left(\frac{u}{\sqrt{3}}\right)$, but if we derive it, then it does not fulfill the function $\frac{1}{2+\cos (x)}$ over the entire interval $[0,2 \pi]$.

(Student responses, 2020)

It should be noted that in the group analysis developed at the end of the class section, through the use of examples and counterexamples, the conditions that must be met for the application of the theorem were discussed.

8. How would you formulate a Variable Change Theorem for definite integrals?

Objective: to propose an approach to the formulation of the change of variable theorem. 
Observations: after having developed a series of activities for the assimilation of the variable change theorem of the integral calculus, the students were expected to formulate an assumption or conjecture with the purpose, on one hand, offavoring the systematization and generalization of the ideas worked, and on the other, to corroborate the effectiveness of the strategy followed from the activity system. It should be noted that 9 of the 16 students with whom we worked raised correct theoretical elements that allowed us to infer that there was a correct approach to a formulation of the change of variable theorem. As an example, we show the following ones.

- Student B: given a function $f(x)$, and the variable change theorem allows to find $F(x)$, such that: $F(x)=\int f(x) d x$, then through a change of variable $\int f^{\prime}(u) \cdot u \prime d x=F(u)+c$, the change of variable is based on a suitable substitution in such a way that the integral is simpler.

- Student E: $\int_{a}^{b} f(x) d x=\int_{a}^{b} \varphi(x) d x$, where $u=\varphi(x) \rightarrow d u=d x$, when using the change of variable also changes the interval.

- Student F: theorem. If $f(x)$ is continuous, then the integral $\int_{a}^{b} f(x) d x=\int_{g(a)}^{g(b)} f(g(u)) g^{\prime}(u) d u$.

- Student J: let $f(x)$ be an integrable function on the interval $[a, b]$ and continuous. When solving for change of variable, we obtain: $\int_{a}^{b} f(x) d x=\int_{u(a)}^{u(b)} u d u$, the function and the limits of integration change, and we evaluate the function in the upper and lower limits obtained when changing the variable.

- Student Q: if a function $f(x)$ is continuous on the interval $[a, b]$, let $u=\varphi(x)$ be differentiable function composed of $f(u)$, then $\int_{a}^{b} f(x) d x=\int_{u(a)}^{u(b)} f(u) u^{\prime} d u$.

(Student responses, 2020)

As a consequence of the analysis of the responses produced, it was identified that the formulations made are not fully formalized and have errors. However, from our own points of view, it is considered that this process of development of the didactic strategy through the system of activities proposed for the approach to a formalization of the theorem of the change of variable in the study of the definite integral in the students of the specialty "Técnico Superior Universitario en Matemáticas Aplicadas" of the Autonomous University of Guerrero, favors the search process of the theorem.

\section{Conclusions}

It is concluded that the proposal of designed and experienced activities of this research contributed some elements that favor the process of assimilation of the concept of change of variable during the resolution of a definite integral, as it could be identified, in the average of responses to the design activities. More than $50 \%$ of the students managed to identify that the change of variable allows transforming the integrand into another function defined in a different interval, but that the solutions of both integrals are equal. On the other hand, they established that under such change of variable, the regions only change in their forms, but the measure of the area prevails in both cases. As a resource, the change of variable facilitates the resolution of the definite integrals.

The treatment of the activities favored an approximation to the theorem of the change of variable in the resolution of the definite integral. We claim that this achievement is due to the work that was carried out with particular cases of definite integrals, in which the interpretation of the change of variable and its use in the resolutions were required. The ideas that were established allowed us to conclude that the system of activities worked can lead students to make their answers more and more argued by mathematics. The latter is favored with the proposal and analysis of situations, where, directly, the change of variable leads to contradictions, and the overcoming of this type of contradiction allows a better approach to the formulation of the change of variable theorem.

This research contributed with a methodological tool for the teacher of the upper and upper-middle level, which benefits their teaching activity and, on the other hand, the system of specific activities, benefit the student at these levels, in the sense that it 
favors the assimilation processes of the change of variable, which makes it possible to improve learning.

Author Contributions: All authors contributed equally. All authors have read and agreed to the published version of the manuscript.

Funding: This research received no external funding.

Institutional Review Board Statement: Not applicable.

Informed Consent Statement: Not applicable.

Data Availability Statement: The data presented in this study are available upon request from an interested researcher. The data are not publicly available because "the group of authors does not coincide with the misuse of the information; therefore, the interested party(s) may have more information about the data reported in the article by expressed request.

Acknowledgments: We acknowledge the support of the group of respondents for their collaboration in answering the surveys for the preparation of this article.

Conflicts of Interest: The authors declare no conflict of interest.

\section{References}

1. Aldana, E.; González, M.T. Comprensión del concepto de integral definida, el caso de un alumno Universitario. In Proceedings of the XIII Simposio de la Sociedad Española de Investigación Matemática (SEIEM), Santander, Spain, 10-12 September 2009.

2. Ricardo, A.; Moya, D. Propuesta metodológica al tratamiento de teoremas y sus demostraciones. EduSol 2007, 7, 1-8.

3. Olave, M. Un Estudio Sobre las Estrategias de los Estudiantes de Bachillerato al Enfrentarse al Cálculo del Área Bajo Una Curva. Ph.D. Thesis, Instituto Politécnico Nacional, Mexico City, México, 2005.

4. Ponce, J.C.; Rivera, A. A discussion on the substitution method for trigonometric rational functions. Math. Comput. Educ. 2011, 45, $44-51$.

5. Llorens, J.; Santonja, F. Una Interpretación de las Dificultades en el Aprendizaje del Concepto de Integral. Divulg. Matemáticas 1997, 5, 61-76.

6. Mejía, O. Percepción de las Nociones de Conservación, Comparación y Cuantificación del Área por Estudiantes Universitarios. Un estudio Socioepistemológico a Través de sus Argumentos. Master's Thesis, (Maestría en Ciencias Área: Matemática Educativa)Facultad de Matemáticas, Universidad Autónoma de Guerrero, Guerrero, México, 2009.

7. Cabañas, M.G.; Cantoral, R. Un Estudio Sobre la Reproducibilidad de Situaciones Didácticas: El Papel de la Noción de Conservación del Área en la Explicación Escolar del Concepto de Integral. IX Simposio Sociedad Española de Investigación en Educación Matemática. 2006. Available online: https://www.seiem.es/docs/comunicaciones/GruposIX/gidam/cabanascantoral.pdf (accessed on 15 July 2021).

8. Díaz, Y.; Cruz, M.; Velázquez, Y.; Molina, S. Estrategias didácticas para desarrollar el proceso de enseñanza-aprendizaje de los contenidos de las Derivadas de funciones reales de una variable real y aplicaciones. Épsilon 2019, 103, 7-23.

9. Morales, A. Estrategia metodológica de carácter heurístico para el estudio de las relaciones de medidas geométricas. Rev. De La Soc. Argent. De Educ. Matemática 2012, 14, 20-31.

10. Paschos, T.; Faumak, V. The reflective abstraction in the construction of the concept of the definite integral. A case study. In Proceedings of the 30th Conference of Internacional Group for the Psychology of Mathematics Education, Prague, Czech Republic, 16-21 July 2006; Novotna, J., Moraova, H., Kretke, M., Stehlikova, N., Eds.; pp. 337-344.

11. Schoenfeld, A.H. Objetivos y métodos de la investigación en educación matemática. La Gac. 2001, 47, $185-205$.

12. Ferreiro, R. Estrategias Didácticas del Aprendizaje Cooperativo. Una Nueva Forma de Enseñar y Aprender: El Constructivismo Social; Trillas: Mexico City, México, 2003.

13. Ferreiro, R. Cómo Ser Mejor Maestro. In El Método ELI; Trillas: Mexico City, México, 2012.

14. García, H.J.; Ortiz, A.M.; Martínez, J.; Tintorer, O. La teoría de la actividad de formación por etapas de las acciones mentales en la resolución de problemas. Rev. Científica Int. Inter Sci. Place 2009, 2, 9.

15. Ausubel, D.P. Adquisición y retención del conocimiento. In Una Perpsectiva Cognitiva; Editorial Paidós Ibérica: Barcelona, Spain, 2002.

16. Ballester, S. ET AL. Metodología de la Enseñanza de la Matemática Tomo I y II. La Habana; Editorial Pueblo y Educación: La Havana, Cuba, 1992.

17. Gagné, R. The Conditions of Learning; Holt, Rinehart and Winston: New York, NY, USA, 1970.

18. Galperin, Y. Introducción a Las Psicología; Pueblo y Educación: La Habana, Cuba, 1985.

19. Leóntiev, A.N. The Genesis of Activity. J. Russ. East Eur. Psychol. 2005, 43, 4. [CrossRef]

20. Piaget, J. La Equilibración de las Estructuras Cognitivas; Problema Central del Desarrollo: Madrid, Spain, 1975.

21. Rogers, C. El proceso de convertirse en persona. In Mi Técnica Terapéutica; Departamento de Psicología y Psiquiatría, Universidad de Winsconsin: Madison, WI, USA, 1992. 
22. Cruz, M. La Enseñanza de la Matemática a Través de la Resolución de Problemas; Educación Cubana: La Habana, Cuba, 2006.

23. Martínez, J.E.; Infante, R.; Brito, M. Los procesos didácticos para el tratamiento de teoremas matemáticos en el nivel medio superior. Univ. Y Soc. 2017, 9, 145-153.

24. Pérez, Y.; Ramírez, R. Estrategias de enseñanza de la resolución de problemas matemáticos. Fundamentos teóricos y metodológicos. Rev. De Investig. 2011, 3, 35.

25. Cedeño, F.O.; Caballero, H.H.; Alcívar, S.; Macías, M. Resolución de problemas estrategia didáctica de Poggioli para mejorar el aprendizaje de la matemática en la educación superior. Rev. Atlante Cuad. Educ. Desarro. Available online: https://www.eumed. net/rev/atlante/2018/11/resolucion-problemas-poggioli.html (accessed on 15 July 2021).

26. Murcia, S.M.; Valdivieso, M.A. Aspectos a considerar en la resolución de un problema. In Proceedings of the II Encuentro Internacional de Matemáticas, Estadística y Educación Matemática, Tunja, Colombia, 14-16 August 2013.

27. Silva, M.; Rodríguez, A.; Santillán, O. Estrategias de Resolución de Problemas Matemáticos Empleados por Estudiantes de Sexto Grado de Primaria. X Congreso Nacional de Matemática Educativa. 2019. Available online: http:/ /www.comie.org.mx/ congreso/memoriaelectronica/v10/pdf/area_tematica_05/ponencias/1729-F.pdf (accessed on 15 July 2021).

28. Sigarreta, J.M.; Laborde, J.M. Estrategia para la resolución de problemas como recurso para la interacción sociocultural. Rev. PREMISA 2004, 20, 15-29.

29. Rubinstein, J. El Desarrollo de la Psicología Principios y Métodos; Consejo Nacional de la Universidad: Habana, Cuba, 1964.

30. Cala, A.; Buendía, A.M.; Herrera, L.J. Métodos y Estrategias Para la Resolución de Problemas Matemáticos: Una Revisión Desde las Investigaciones de la Última Década; Proyecto de Investigación: Medellín, Colombia, 2017.

31. Campistrous, L.; Rizo, C. Estrategias de resolución de problemas en la escuela Cuba. Rev. Latinoam. De Investig. En Matemática Educ. 1999, 2, 31-45.

32. Campos, M. The job of the heuristic procedures in the resolution of geometric exercises. Boletin REDIPE 2019, 8, 185-193.

33. Polya, G. Cómo Plantear y Resolver Problemas; Trillas: México City, México, 1999.

34. Santos-Trigo, M.; Moreno-Armella, L.; Camacho-Machín, M. Problem solving and the use of digital technologies within the mathematical working space framework. ZDM Math. Educ. 2016, 48, 827-842. [CrossRef]

35. Schoenfeld, A. Mathematical Problem Solving; Academic Press: Orlando, FL, USA, 1985.

36. Valle, M.C.; Curotto, M.M. La resolución de problemas como estrategia de enseñanza y aprendizaje. Rev. Electrónica De Enseñanza De Las Cienc. 2008, 7, 2. 